\title{
An evaluation of COSMIC radio occultation data in the lower atmosphere over the Southern Ocean
}

\author{
L. B. Hande ${ }^{1}$, S. T. Siems ${ }^{1}$, M. J. Manton ${ }^{1}$, and D. H. Lenschow ${ }^{2}$ \\ ${ }^{1}$ School of Earth, Atmosphere and Environment, ARC Centre of Excellence for Climate System Science, Monash University, \\ Melbourne, Australia \\ ${ }^{2}$ National Center for Atmospheric Research, Boulder, Colorado, USA
}

Correspondence to: L. B. Hande (luke.hande@gmail.com)

Received: 18 August 2014 - Published in Atmos. Meas. Tech. Discuss.: 19 September 2014

Revised: 12 December 2014 - Accepted: 15 December 2014 - Published: 9 January 2015

\begin{abstract}
The global positioning system (GPS) radio occultation (RO) method is a relatively new technique for taking atmospheric measurements for use in both weather and climate studies. As such, this technique needs to be evaluated for all parts of the globe. Here, we present an extensive evaluation of the performance of the Constellation $\mathrm{Ob}$ serving System for Meteorology, Ionosphere, and Climate (COSMIC) GPS RO observations of the Southern Ocean boundary layer. The two COSMIC products used here are the "wetPrf" product, which is based on 1-D variational analysis with European Centre for Medium-Range Weather Forecasts (ECMWF), and the "atmPrf" product, which contains the raw measurements from COSMIC. A direct comparison of temporally and spatially co-located COSMIC profiles and high resolution radiosonde profiles from Macquarie Island $\left(54.62^{\circ} \mathrm{S}, 158.85^{\circ} \mathrm{E}\right)$ highlights weaknesses in the ability of both COSMIC products to identify the boundary layer structure, as identified by break points in the refractivity profile. In terms of reproducing the temperature and moisture profile in the lowest $2.5 \mathrm{~km}$, the "wetPrf" COSMIC product does not perform as well as an analysis product from the ECMWF. A further statistical analysis is performed on a large number of COSMIC profiles in a region surrounding Macquarie Island. This indicates that, statistically, COSMIC performs well at capturing the heights of main and secondary break points. However, the frequency of break points detected is lower than the radiosonde profiles suggest, but this could be simply due to the long horizontal averaging in the COSMIC measurements. There is also a weak seasonal cycle in the boundary layer height similar to that observed in the radiosonde data, providing some confidence in the ability of COSMIC to detect an important boundary layer variable.
\end{abstract}

\section{Introduction}

The structure and dynamics of the atmospheric boundary layer (ABL) not only directly impact the weather, through the transport of scalars such as water vapour, but also the climate, most obviously through their role in the formation and dissipation of clouds. The ABL height is an important variable, which is controlled by a balance of large-scale subsidence tending to decrease the ABL height and turbulent processes tending to increase the ABL height (Stull, 1988). The exact definition of the ABL height is ambiguous, making it difficult to quantify and study, particularly as routine observations of the depth of the boundary layer are generally not available over much of the globe. This problem is exacerbated over remote locations, such as the Southern Ocean, where in situ observations are sparse. Given that clouds over the Southern Ocean is responsible for large biases in modelled net radiation (Trenberth and Fasullo, 2010), it is important to understand the fundamental processes at work in this region, which is dominated by the presence of boundary layer cloud year round (Huang et al., 2012a).

Huang et al. (2012a) present a climatology of Southern Ocean clouds from CloudSat, and identify weaknesses in the ability of CloudSat to identify low clouds due to interference with the surface. This finding was reinforced by Huang et al. (2012b), who found similar difficulties with other satellite products. The height of clouds is strongly correlated with the height and structure of the boundary layer. Hande et al. (2012b) present a detailed study of the structure of the ABL over the Southern Ocean from in situ measurements taken from Macquarie Island $\left(54.62^{\circ} \mathrm{S}, 158.85^{\circ} \mathrm{E}\right)$. The observations from radiosonde data suggest that the $\mathrm{ABL}$ is shallow and often decoupled, a feature manifested as multiple lay- 
ers in the lowest few kilometres, and these features are not well captured in a state-of-the-art reanalysis data set from the ECMWF. It was shown that the reanalysis data set had a median primary inversion about $200 \mathrm{~m}$ lower than the radiosonde data. An analysis of proxy cloud fields from the radiosondes indicated that the low-level clouds are not typically capping a well-mixed boundary layer, in stark contrast to the well-studied subtropical stratocumulus in the Eastern Pacific and Atlantic (e.g. Albrecht et al., 1995; Bretherton et al., 2004). Furthermore, multiple cloud layers were observed to exist both within, and above the ABL. This supports earlier field observations of boundary layer decoupling in regions with less subsidence as typified in the First Aerosol Characterization Experiment (ACE-1) (Boers and Krummel, 1998; Russell et al., 1998). During ACE-1, as well as the Southern Ocean Cloud Experiments (SOCEX) (Jensen et al., 2000), a main inversion in virtual potential temperature was observed below $2 \mathrm{~km}$ from aircraft data, with a weaker inversion below the main inversion. Cloud was observed throughout this decoupled boundary layer.

Another distinctive feature of the Southern Ocean is high wind speeds and wind shear (Hande et al., 2012b; Xiaojun, 2004), producing some of the largest observed wave heights on the globe (Vinoth and Young, 2011). These conditions lead to the possibility of significant sea spray being injected into the boundary layer. This could have an, as yet, unaccounted for effect on the thermodynamics of the boundary layer, as well as the cloud microphysics (Andreas, 1998). With observations supporting an increase in the strength of the Southern Hemisphere westerlies over recent decades (Young et al., 2011; Hande et al., 2012a), the potential longterm impact of these effects on the Southern Ocean boundary layer, as well as the associated clouds, could be significant.

Sokolovskiy et al. (2006) demonstrated the usefulness of using global positioning system (GPS) radio occultation (RO) data to study the ABL height. They found that estimating the ABL height from the refractivity profile provided good agreement with radiosonde and reanalysis data sets. Most commonly used methods for determining the ABL height from GPS RO data involve identifying large gradients in the refractivity profile (Ao et al., 2012; Basha and Ratnam, 2009). A global analysis of ABL heights was performed by Guo et al. (2011) from GPS RO data. Their technique involved looking for a break point, or first-order discontinuities, in the refractivity profile, which served as an indicator of the ABL top. It was shown to agree well with boundary layer heights estimated from high-resolution radiosonde observations, particularly in the subtropical high-pressure regions where there is often a well-defined decrease in moisture above the main inversion. Chan and Wood (2013) use a similar technique to study the global variability of the ABL height. The authors find good agreement of ABL heights between COSMIC and radiosonde data on seasonal timescales.

Similarly, Seidel et al. (2010) present a climatology of ABL heights using several methods to estimate the heights from a number of different measurement systems. That study concludes that ABL heights based on the profile of refractivity do not agree with those based on gradients of other meteorological variables, particularly in the presence of clouds. There are large differences between different methods to calculate the PBL top in the presence of clouds, due to large humidity lapses over cloud top which can commonly lead to higher PBL heights when calculated from the humidity gradient. This conclusion is quite poignant, particularly for a cloud-dominated region such as the Southern Ocean.

The aim of this study is to evaluate the performance of the GPS RO technique of measuring boundary layer height, and other significant inversions, as well as the ability of the "wetPrf" COSMIC product to reproduce the temperature and moisture profiles within the boundary layer. An evaluation of this COSMIC data product is needed in this region because the structure of the boundary layer is unlike that of the tropical and subtropical high-pressure region, where the break point method for determining the ABL height has been shown to perform well.

\section{Observational and analysis data}

\subsection{COSMIC}

The Constellation Observing System for Meteorology, Ionosphere, and Climate (COSMIC)/Formosa Satellite 3 (FORMOSAT-3) is a constellation of six identical microsatellites each carrying a GPS RO receiver (Anthes et al., 2008). This allows for around 1500-2000 soundings per day around the globe, from 2006 onwards. The COSMIC measurement process is outlined by Kursinski et al. (1997), and summarized below. The primary measurement is of the Doppler shift of a radio signal that is emitted from the GPS satellite, occulted by Earth's atmosphere, and received by the Low Earth Orbiting satellite on the opposite side of the atmospheric limb. From this, a bending angle is derived, then the refractivity can be computed as a vertical integral of the bending angle from the top of the atmosphere down. The limb scanning geometry, either rising or setting occultations, is produced by the relative motion of the two satellites.

The raw measurements of the refractivity are used to identify the ABL height using the common technique of identifying break points in the refractivity profile, to be discussed in Sect. 3. This technique amounts to computing the vertical derivative of the refractive index, essentially reverting back to the bending angle measurement. This "atmPrf" data set contains approximately 802 data points in the lowest $3 \mathrm{~km}$, and will be referred to as the COSMIC raw data set, where appropriate. 
In the neutrally charged atmosphere, the refractive index $(N)$ can be related to the pressure $(p)$, temperature $(T)$ and water vapour pressure $(e)$ by

$N=77.6 \frac{p}{T}+3.73 \times 10^{5} \frac{e}{T^{2}}$,

where $T$ is in Kelvin, and $p$ and $e$ are in hPa. With the aid of the hydrostatic equation, Eq. (1) can be used to estimate vapour pressure if temperature is specified, and vice versa. In this study, the "wetPrf" product was also used, which combines the raw observations with moisture information from the ECMWF TOGA 2.5 analysis using 1-D variational analysis. The ECMWF analysis product is used as a first guess for moisture below $10 \mathrm{~km}$. The resulting profile is interpolated onto $100 \mathrm{~m}$ levels to produce the "wetPrf" profiles. Therefore in this data set, information on moisture and temperature is available at the expense of the high vertical resolution available in the raw refractivity measurements. The refractivity used in the "wetPrf" data set is the analysed refractivity, not the raw measurements. There are, on average, 31 data points in the lowest $3 \mathrm{~km}$ of the profiles over the Southern Ocean, and 400 levels available for the whole sounding. For the sake of clarity, this data product will be referred to as the $\mathrm{COSMIC}_{\text {wet }}$ data set. The profiles are constructed from $50 \mathrm{~km}$ long horizontal transects which cover the lowest $3 \mathrm{~km}$. Therefore, the profiles from both COSMIC products would represent an average of the conditions over this line.

\subsection{ECMWF analysis}

The European Centre for Medium-Range Weather Forecasts (ECMWF) has a number of data products providing global coverage of various atmospheric variables. The ECMWF TOGA 2.5 global Upper Air Analysis data set (ECMWF, 1990 ) is used here to understand the influence of the background data in the 1-D variational data assimilation. The process of 1-D variational analysis uses the estimates of moisture from the ECMWF data to produce the $\mathrm{COSMIC}_{\mathrm{wet}}$ measurements. This analysis data set is not independent of the other data sets considered here. The Macquarie Island radiosonde profiles are used in the assimilation process, however their contribution to the reanalysis data is weighted depending on the error characteristics of this data set. These error characteristics are determined by comparing these observations to others in this regions, mostly from satellite-based platforms over the Southern Ocean. When there is agreement between the various observations, the radiosonde data receive a higher weighting, and vice versa. These radiosonde data will be used for the evaluation of the thermodynamics for a limited number of cases. In addition to the radiosonde data, the ECMWF also assimilates the GPS RO data used in this study. Atmospheric profiles from ECMWF represent box-averaged quantities. Thus, these profiles represent the regional conditions over a larger portion of the ocean than the radiosonde profiles.

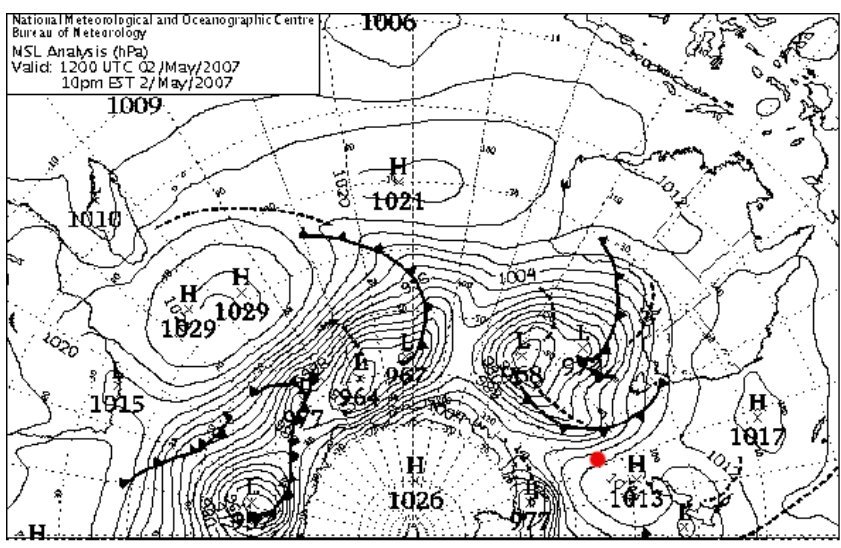

Figure 1. MSLP chart for 2 May 2007 at 12Z. The approximate location of Macquarie Island is shown by the red dot. (Source: Australian Bureau of Meteorology.)

\subsection{Macquarie Island}

Macquarie Island, located at $54.62^{\circ} \mathrm{S}, 158.85^{\circ} \mathrm{E}$, is one of the few Southern Ocean islands with a dedicated meteorological station. Here, radiosondes are released twice daily from an altitude of $8 \mathrm{~m}$, with direct exposure to the prevailing westerly winds. The data set used here (MAC) consists of the $10 \mathrm{~s}$ vertical resolution soundings covering the period 1995 2014, consisting of 13396 soundings. On average, there are 171 measurements in the lowest $3 \mathrm{~km}$ of the atmosphere. The profiles from the radiosonde represent a point measurement, and as such would be much more representative of the local conditions around Macquarie Island, rather than the regional conditions in the Southern Ocean. The difference in measurement techniques between the three data sets will contribute to differences in their respective representations of the atmospheric conditions.

The lack of observations at these high latitudes compared to other regions with better coverage of observations reduces the accuracy of numerical weather prediction (Adams, 1997). As a result, the location and extent of cold fronts, for example, can be inaccurate. The frequency of fronts passing over Cape Grim, Tasmania, was determined by Jimi et al. (1997) to be up to twice a week.

Figure 1 shows an example of a mean sea level pressure (MSLP) chart over much of the Southern Ocean, with the approximate location of Macquarie Island shown by the red dot. It is interesting to note the complicated frontal structures associated with the low-pressure systems over the Southern Ocean south of Australia. Hence, determining the exact synoptic conditions during each COSMIC or MAC profile may be prone to error. 


\section{Determining the ABL depth}

A method for determining the height of the atmospheric boundary layer similar to Guo et al. (2011) is implemented for this study, and outlined below. We look for a break point in the $N(z)$ profile between 100 and $2500 \mathrm{~m}$ by defining an approximately $300 \mathrm{~m}$ sliding window and calculating the gradient of a linear regression of the form $A z+B$ within the window. The break point, which we use as an estimate of ABL height, is defined as the maximum difference of $A$ from the windows immediately above and below the break point. A minimum value of $50 \mathrm{~km}^{-1}$ for the gradient of the window immediately below the break point of the main inversion is required. A detailed description of the method is outlined in Guo et al. (2011), including an example of how the method identifies inversions in sounding profiles. A secondary break point, or inversion, is defined in the same way, with a maximum height of $80 \%$ of the height of the main inversion, and a minimum value of $40 \mathrm{~km}^{-1}$ for the gradient of the linear regression immediately below the secondary inversion. The requirement for having a weaker inversion below a main inversion ensures consistency with previous observations of the Southern Ocean boundary layer (Russell et al., 1998; Jensen et al., 2000), and is also commonly observed in other marine environments (Rémillard et al., 2012).

The magnitude of the gradient defining the secondary inversion is weaker than the main inversion, and hence differs from Guo et al. (2011). This value was chosen so the mean and standard deviation for the height of the secondary inversions, and also the frequency of occurrence for the MAC data set, were roughly the same as Hande et al. (2012b), who defined the ABL height based on the virtual potential temperature profile from soundings. Changing the value of the gradient below the break point by $\pm 5 \mathrm{~km}^{-1}$ had little effect on the height of inversions, with changes less than $15 \mathrm{~m}$, but changed the frequency of occurrence by approximately $\pm 16 \%$ for secondary inversions.

The above method for determining the ABL height relies on identifying changes in the refractivity profile. However, it is changes in the temperature and moisture which are often used to define the top of the ABL. So at this point it is worthwhile considering how changes in the refractivity relate to changes in temperature and moisture. Differentiating Eq. (1) with height gives

$$
\begin{aligned}
\frac{\mathrm{d} N}{\mathrm{~d} z}= & 77.6 \frac{1}{T} \frac{\mathrm{d} p}{\mathrm{~d} z}-77.6 \frac{p}{T^{2}} \frac{\mathrm{d} T}{\mathrm{~d} z}+3.73 \times 10^{5} \frac{1}{T^{2}} \frac{\mathrm{d} e}{\mathrm{~d} z} \\
& -7.46 \times 10^{5} \frac{e}{T^{3}} \frac{\mathrm{d} T}{\mathrm{~d} z} .
\end{aligned}
$$

This shows that gradients in $N(z)$ are linked to gradients in temperature and vapour pressure, which are of the opposite sign. Therefore, the break point technique is most sensitive to a temperature increase and a moisture decrease occurring together. This is typical of a sub-tropical marine boundary layer. However, Hande et al. (2012b) showed that this struc- ture only occurs in around $18 \%$ of radiosonde data analysed over the Southern Ocean. Both temperature and vapour pressure can increase above the ABL, and in this case the refractivity may not necessarily change across the ABL top, and hence no ABL top detected. This was confirmed by tests on idealized profiles which were constructed from a series of straight-line segments with either a temperature or moisture increase or decrease inserted into the profile within the lowest $2 \mathrm{~km}$. The break point method in the refractivity profile often failed to detect an ABL top in the presence of an increase in vapour pressure, even if this occurred at the same level as a strong temperature increase. Obviously this depends on the magnitude of the changes in temperature and moisture; however, the respective magnitudes were chosen to be consistent with observations from MAC.

Chan and Wood (2013) show that the changes in moisture contribute about an order of magnitude more than changes in temperature to the refractivity profile. This has the potential to complicate the ABL top detection over the Southern Ocean, where multiple cloud layers are common, meaning that multiple significant gradients in moisture may be present in the lowest few kilometres.

\section{Case study evaluation of COSMIC}

\subsection{Boundary layer height}

Here we use the MAC data set to make a direct comparison with spatially and temporally co-located profiles from COSMIC to evaluate the performance of the RO technique over the Southern Ocean. COSMIC profiles from within a $2 \times 2$ degree box around Macquarie Island occurring within $\pm 1 \mathrm{~h}$ of the radiosonde launches were considered to be co-located. In addition to this, the COSMIC soundings were required to penetrate to within $500 \mathrm{~m}$ of the surface. For the period 2006-2013, only 35 soundings were found to coincide. The small sample is a result of three constraints: the time window, the size of the box, and the requirement to penetrate to below $500 \mathrm{~m}$. Relaxing these constraints makes the sample bigger, but less relevant to the local conditions around Macquarie Island. The conclusions presented in this evaluation were drawn from the analysis of all the co-located profiles. However, to emphasize the typical ABL structures encountered over the Southern Ocean, only the results from four profiles will be shown. These four examples are shown in Figs. 2 to 5.

From the MAC data, Figs. 2 and 4 represent the case where multiple layers are found in the lowest few kilometres. These two cases have similar meteorological conditions. Both profiles represent pre-frontal conditions with northerly winds, and high values of relative humidity indicates that cloud exists throughout the boundary layer in both cases. Figure 3 represents a well-mixed boundary layer with a strong temperature inversion, and a decrease in the vapour pressure oc- 

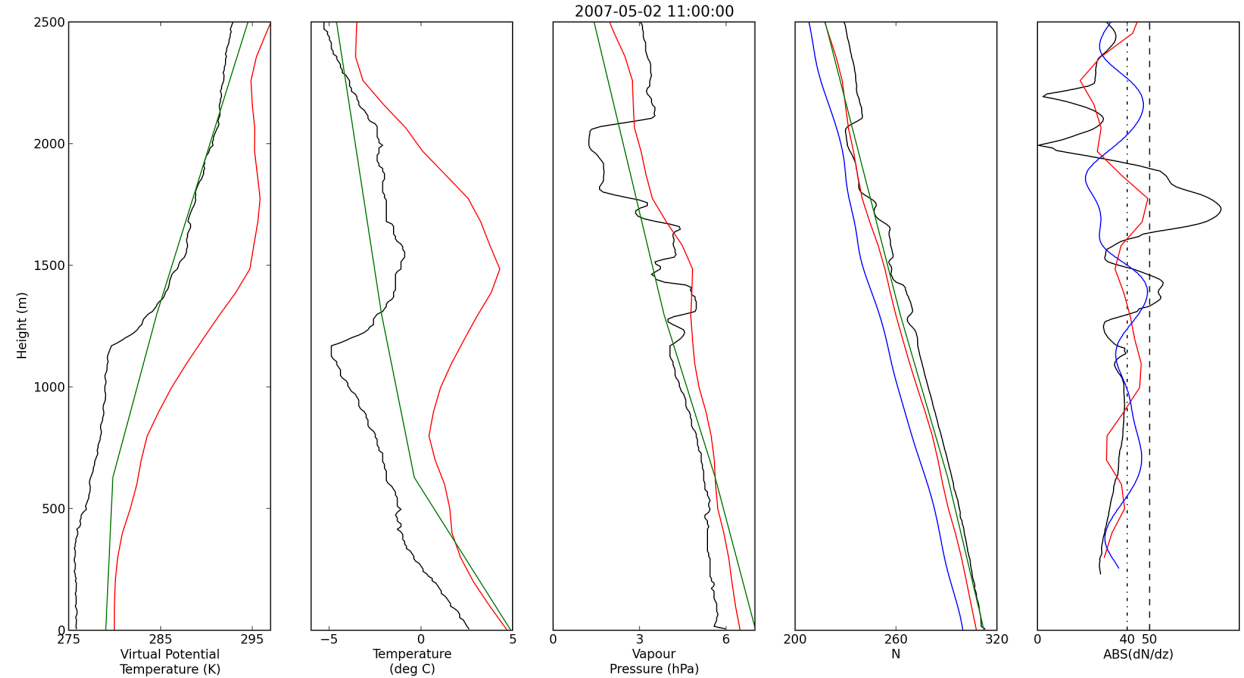

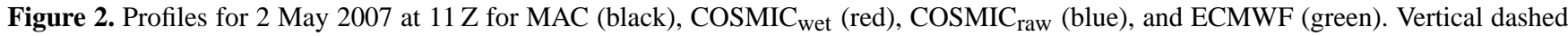
(dash-dotted) line represents the threshold defining main (secondary) break point.
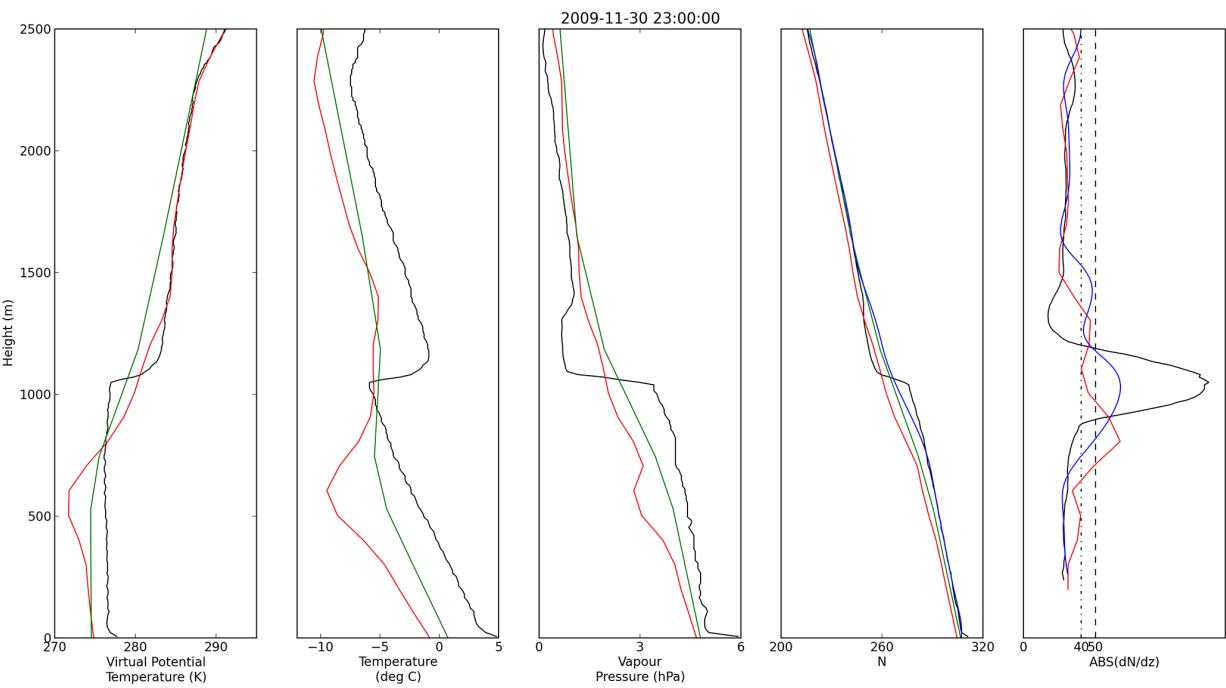

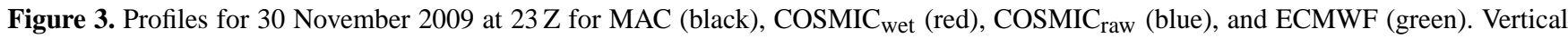
dashed (dash-dotted) line represents the threshold defining main (secondary) break point.

curring at the same height. The MSLP chart corresponding to Fig. 3 shows that Macquarie Island is under the influence of a high-pressure system, centred just south of Tasmania. There is a sharp drop in the relative humidity just over $1000 \mathrm{~m}$, indicating a well-defined cloud top at the same height. This structure represents a typical boundary layer, not unlike those found in the sub-tropics where the break-point method on the refractivity profile has been found to work well (Guo et al., 2011). Finally, Fig. 5 shows no distinctive features, and a more-or-less stably stratified layer extending from about $500 \mathrm{~m}$ to above $2.5 \mathrm{~km}$. This final profile is also under the influence of a high-pressure system to the north which produces westerly surface winds. In all the profiles, the black lines represent the MAC profile, the red is the $\mathrm{COSMIC}_{\mathrm{wet}}$ product, the green is the background ECMWF analysis profile, and the blue refractivity profile is the raw refractivity measurements from the $\mathrm{COSMIC}_{\text {raw }}$ product.

The heights of any main and secondary break points detected in the various data sets are shown in Table 1 . The height of the break points in the refractivity profile (N-bp) are shown for all data sets. However, the heights from the ECMWF data are not shown because the vertical resolution is too low for a $300 \mathrm{~m}$ sliding window. As a more conventional measure of any main and secondary inversions, the gradient in virtual potential temperature $\left(\frac{\mathrm{d} \theta_{\mathrm{v}}}{\mathrm{d} z}\right)$ in the MAC data set is also shown. 

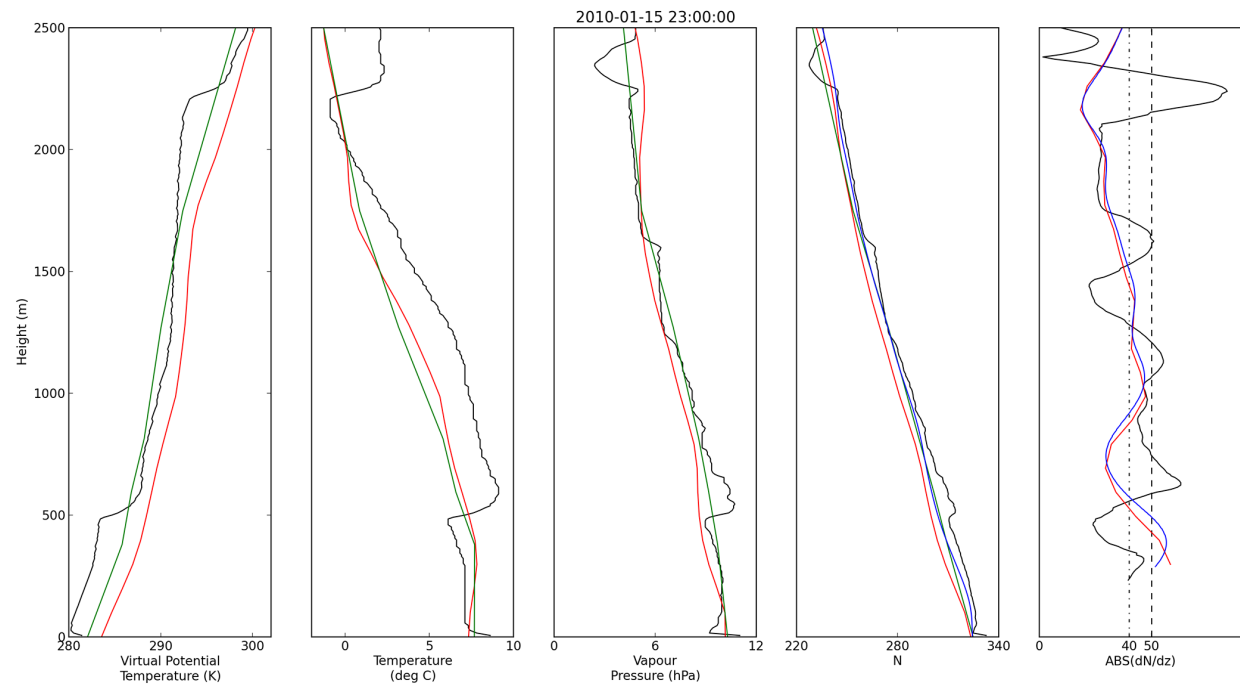

Figure 4. Profiles for 15 January 2010 at $23 \mathrm{Z}$ for MAC (black), COSMIC wet $_{\text {(red), COSMIC }}$ raw (blue), and ECMWF (green). Vertical dashed (dash-dotted) line represents the threshold defining main (secondary) break point.
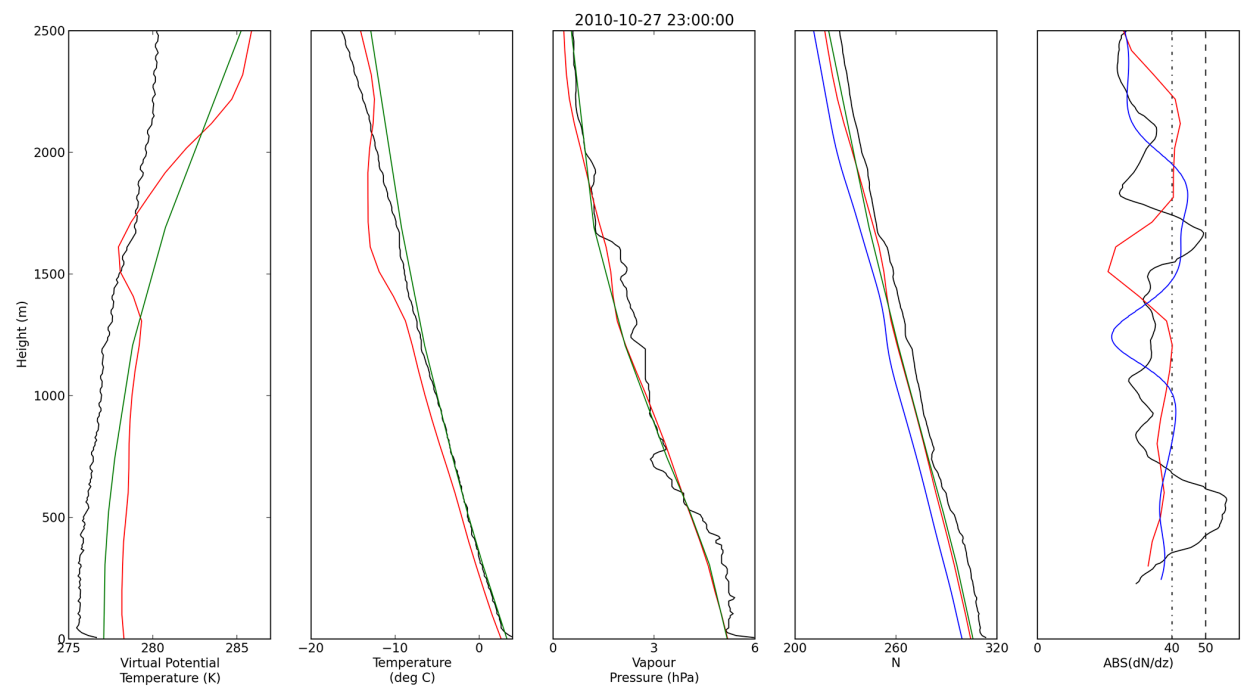

Figure 5. Profiles for 27 October 2010 at $23 \mathrm{Z}$ for MAC (black), COSMIC wet $_{\text {(red), COSMIC }}$ (blue), and ECMWF (green). Vertical dashed (dash-dotted) line represents the threshold defining main (secondary) break point.

Figure 2 shows two clear inversions in virtual potential temperature in the MAC data set, however only one break point in the refractivity profile is detected. The vapour pressure increases above both temperature inversions at about 500 and $1200 \mathrm{~m}$, so that the vertical change in refractivity is mostly cancelled out by the coincident increases in temperature and vapour pressure. The red profile shows that the $\mathrm{COSMIC}_{\text {wet }}$ product has the same qualitative behaviour as MAC, however it is consistently slightly warmer and more moist. There are no break points detected here. Interestingly, the higher vertical resolution of the COSMIC raw $_{\text {product, }}$ shown as the blue refractivity profile, also fails to detect any break points. The final panel shows the absolute magnitude of the gradient in refractivity within a $300 \mathrm{~m}$ window. The dashed line and the dash-dotted line indicate the thresholds for the main and secondary inversion respectively. Gradients in the refractivity of the $\mathrm{COSMIC}_{\text {wet }}$ and COSMIC raw products do not agree in this example.

An example of a well-mixed boundary layer is shown in Fig. 3. There is a strong temperature increase and a corresponding moisture decrease around $1100 \mathrm{~m}$. This feature is identified by both the break point method, as well as the virtual potential temperature gradient method in the MAC data. Here, the break points in the COSMIC profiles show very good agreement with the MAC data set. The COSMIC product identifies the break point at the same location as the 
Table 1. Main and secondary inversion heights for MAC and COSMIC using the refractivity profile break point method (N-bp) and the $\frac{\mathrm{d} \theta_{\mathrm{v}}}{\mathrm{d} z}$ method for MAC.

\begin{tabular}{|c|c|c|c|c|c|c|c|c|}
\hline \multirow[b]{2}{*}{ Profile } & \multicolumn{2}{|c|}{ COSMIC $_{\text {wet }}$ N-bp } & \multicolumn{2}{|c|}{ COSMIC $_{\text {raw }}$ N-bp } & \multicolumn{2}{|c|}{ MAC N-bp } & \multicolumn{2}{|c|}{ MAC $\frac{\mathrm{d} \theta_{\mathrm{v}}}{\mathrm{d} z}$} \\
\hline & Main & $\mathrm{Sec}$ & Main & $\mathrm{Sec}$ & Main & $\mathrm{Sec}$ & Main & $\mathrm{Sec}$ \\
\hline Figure 2 & - & - & - & - & 1909 & - & 1188 & 494 \\
\hline Figure 3 & 907 & - & 1187 & - & 1178 & - & 1069 & - \\
\hline Figure 4 & 495 & - & 595 & - & 2353 & 1262 & 499 & 178 \\
\hline Figure 5 & - & - & - & - & 663 & 520 & - & - \\
\hline
\end{tabular}

main inversion in the MAC data. However, the gradient in the refractivity is much smaller. The $\mathrm{COSMIC}_{\text {wet }}$ product identifies a break point about $200 \mathrm{~m}$ lower than the other data sets.

Another decoupled boundary layer is shown in Fig. 4. Here the strongest inversion is at $500 \mathrm{~m}$, with a weaker inversion aloft at $2200 \mathrm{~m}$. The higher inversion is detected by the break point method. However, since there is an increase in both moisture and temperature at $500 \mathrm{~m}$, the break point method fails to detect the lower one. The COSMIC ${ }_{\text {wet }}$ product has a break point in the refractivity profile at $495 \mathrm{~m}$, nicely coinciding with the main inversion in MAC. Similarly, the COSMIC $_{\text {raw }}$ product identifies a break point at $595 \mathrm{~m}$, in approximately the same location. Notice that there is a strong gradient in the refractivity profile from MAC around $600-700 \mathrm{~m}$. This is not identified as a break point since the difference in the gradients between adjacent windows is not larger than those associated with the feature around $1200 \mathrm{~m}$. Also notice that the refractivity gradients of the two different COSMIC products agree very well.

According to the MAC profile in Fig. 5, there are no significant features in either the temperature or vapour pressure. One would expect no break points or virtual temperature inversions to be detected, which is true for all but the MAC data set. Here there are two break points in the refractivity profile associated with some slight variability in the vapour pressure between about 300 and $700 \mathrm{~m}$.

As a general observation from the 35 co-located profiles, the break point in the refractivity profile from either COSMIC products rarely aligns with a virtual potential temperature inversion from the high-resolution MAC soundings. The $\mathrm{COSMIC}_{\text {raw }}$ product identifies marginally more break points (16 main and 9 secondary) than the $\mathrm{COSMIC}_{\text {wet }}$ product (15 main and 7 secondary), and there appears to be no systematic difference in height between the two COSMIC data products, or the MAC data set. The common method for identifying the ABL top by identifying large gradients in virtual potential temperature would be inappropriate to use on the $\mathrm{COSMIC}_{\text {wet }}$ data. The diagnostic variables from $\mathrm{COSMIC}_{\text {wet }}$, such as virtual potential temperature, which are derived from a combination of the ECMWF analysis and the raw refractivity (which is in turn derived from the bending angle, which is derived from the first-order measurement of a Doppler shift) are not always consistent with in situ sound-

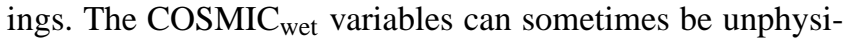
cal, such as having superadiabatic layers, as shown in Figs. 3 and 5 .

\subsection{Thermodynamics}

Here we present an evaluation of the ability of the $\mathrm{COSMIC}_{\text {wet }}$ product and the ECMWF data to reproduce the temperature and moisture profiles of the MAC soundings. The root mean squared error (RMSE) for temperature and vapour pressure, calculated using the differences between MAC and COSMIC ${ }_{\text {wet }}$, and MAC and ECMWF at three levels in the atmosphere are shown in Table 2. In order to reduce interpolation errors of the data sets, the closest level to 500, 1500 and $2500 \mathrm{~m}$ were used as the three levels. The RMSE for each co-located profile and each variable is defined as

RMSE $=\sqrt{\sum_{l=1}^{3}\left(\mathrm{MAC}_{l}-\operatorname{COSMIC}_{\text {wet }, l}\right)^{2}}$,

where $\mathrm{MAC}_{l}$ is the observed variable from the MAC profile at level $l$, and $\operatorname{COSMIC}_{\text {wet, } l}$ is the same for the co-located COSMIC $_{\text {wet }}$ profile. The RMSE $E_{\text {total }}$ for each variable is just the root mean squared error of each co-located RMSE for that variable. That is,

$\mathrm{RMSE}_{\text {total }}=\sqrt{\sum_{p=1}^{35} \mathrm{RMSE}_{\mathrm{p}}^{2}}$,

where $\mathrm{RMSE}_{\mathrm{p}}$ is the RMSE for each co-located profile.

The quantitative analysis shown in Table 2 indicates that

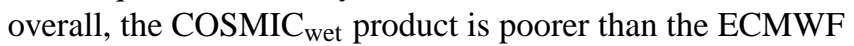
data at reproducing the MAC temperature and vapour pressure. Out of the four profiles shown earlier, only the temperature in Fig. 4 and the vapour pressure in Figs. 2 and 5 from COSMIC $_{\text {wet }}$ perform better than ECMWF. Over the 35 colocated profiles, the ECMWF data outperform $\mathrm{COSMIC}_{\mathrm{wet}}$ for temperature and vapour pressure, showing the lowest $\mathrm{RMSE}_{\text {total }}$ for both these variables. This is likely due to the fact that the MAC soundings have been assimilated into the ECMWF data set used here.

Qualitatively, it can be seen that the background ECMWF profiles fail to capture any of the virtual potential tempera- 


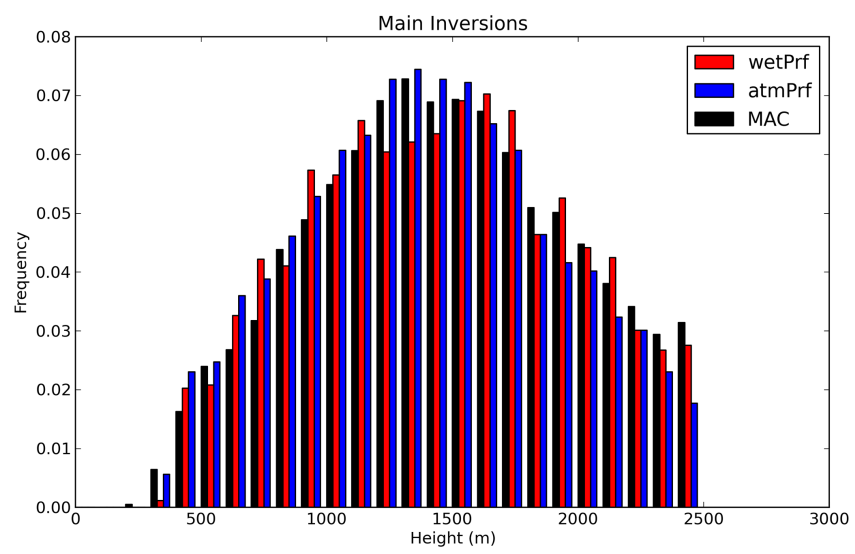

Figure 6. Main refractivity break point for MAC (black), COSMIC $_{\text {wet }}$ (red), COSMIC raw (blue).

ture inversions which would typically define the ABL top.

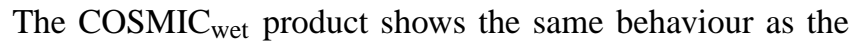
background ECMWF data. COSMIC ${ }_{\text {wet }}$ does appear to have slightly more variability in most of the 35 co-located profiles, however it often produces unphysical superadiabatic layers for example, in Figs. 3 and 5. Figure 2 is interesting in that the COSMIC $_{\text {wet }}$ profile appears to show the same features in the virtual potential temperature as the MAC data, only offset by several degrees. This raises the possibility that, given a higher resolution, and more accurate representation of either the temperature or moisture for the 1D-Var process, the performance of the $\mathrm{COSMIC}_{\mathrm{wet}}$ data in reproducing the thermodynamics and ABL height could be improved.

Schreiner et al. (2007) identify horizontal heterogeneity as a potential source of error in the GPS RO profiles in the neutrally charged atmosphere. In order to estimate this effect, we consider the impact of a front on the results. An approximate distance to the nearest front, based on MSLP charts, is given in Table 2. The distance to the nearest front is given in 5 degree increments in order to reflect the inherent uncertainty in the precise location of the frontal system. Figure 1 is the MSLP chart for the profile shown in Fig. 2, and shows Macquarie Island under the influence of a northerly pre-frontal air mass.

There does appear to be a relationship between the performance of $\mathrm{COSMIC}_{\mathrm{wet}}$ in reproducing the thermodynamics, and the structure of the ABL, as well as a weak relationship to the synoptic meteorology. Analysis of the four best and four worst performing $\mathrm{COSMIC}_{\text {wet }}$ profiles, as judged by the RMSE, showed that the best performance of COSMIC $\mathrm{wet}_{\mathrm{w}}$ in reproducing the thermodynamics occurred when the profile was stably stratified with no, or only weak inversions and little variability in the profile. These four profiles were typically closer to a cold front, suggesting that the influence of a front is to produce a stably stratified ABL with no strong inversions. On the other hand, the four worst performing profiles in reproducing the moisture and tempera-

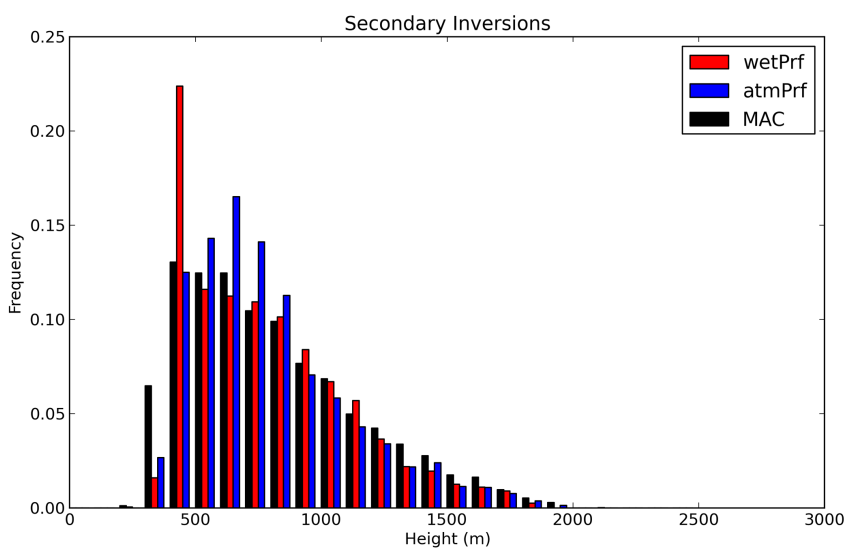

Figure 7. Secondary refractivity break point for MAC (black), COSMIC $_{\text {wet }}$ (red), COSMIC raw (blue).

ture mostly represented well-mixed ABLs of between 500 and $1200 \mathrm{~m}$ depth, with strong temperature inversions and a decrease in vapour pressure occurring together. Figure 3 is one of the four worst performing profiles, which shows a well-defined temperature inversion along with a decrease in moisture around $1000 \mathrm{~m}$. These profiles with strong inversions tended to be further away from a front. Hande et al. (2012b) showed that reanalysis products typically have difficulty capturing strong changes in temperature or moisture near Macquarie Island. Hence, a possible explanation for this is the difficulty of the background ECMWF data to identify large gradients in temperature or moisture, and the influence this has on the COSMIC wet $_{\text {product. }}$

\section{Local statistical evaluation}

To gain a broader appreciation of the performance of both the COSMIC products, we present a statistical analysis of the height and occurrence of main and secondary inversions. COSMIC RO data from a $10 \times 10$ degree box around Macquarie Island are used, in order to gain a good statistical sample size. In total, this amounts to 7768 profiles for the COSMIC $_{\text {wet }}$ product, and 7469 for the COSMIC raw $_{\text {product }}$ over the period 2006-2013. Previous studies (Huang et al., 2012a; Hande et al., 2012b) show that there are only very weak diurnal and seasonal cycles in thermodynamic and cloud properties over the Southern Ocean. Hence, any difference in the temporal distribution of the two data sets should not affect the statistics. Figures 6 and 7 show the distribution of main inversions and secondary inversions from both COSMIC products and MAC.

A main inversion was detected in 3559 of the COSMIC $\mathrm{Cet}_{\text {wet }}$ soundings, and a secondary inversion in 2002 cases. For the COSMIC $_{\text {raw }}$ product, a main inversion was detected in 3622 soundings, and a secondary inversion in 2210 profiles. Finally, for the MAC data set, a main inversion occurred in 8944 soundings, and a secondary inversion in 5136 sound- 


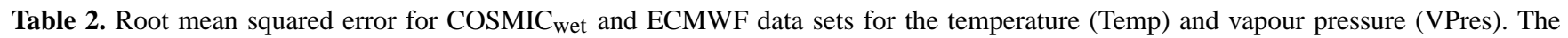
approximate distance to a front is also shown in degrees. The letter indicates whether the front is to the west (W) or east (E) of Macquarie

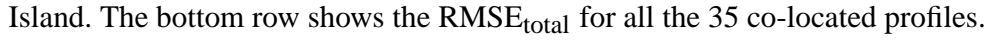

\begin{tabular}{cccccc}
\hline & $\begin{array}{c}\text { COSMIC } \\
\text { Temp }\left({ }^{\circ} \mathrm{C}\right)\end{array}$ & $\begin{array}{c}\text { ECMWF } \\
\text { Temp }\left({ }^{\circ} \mathrm{C}\right)\end{array}$ & $\begin{array}{c}\text { COSMIC }_{\text {wet }} \\
\text { VPres }(\mathrm{hPa})\end{array}$ & $\begin{array}{c}\text { ECMWF } \\
\text { VPres (hPa) }\end{array}$ & $\begin{array}{c}\text { Dist to } \\
\text { Front (deg) }\end{array}$ \\
\hline Figure 2 & 6.0 & 2.51 & 1.05 & 1.18 & $10-15 \mathrm{~W}$ \\
Figure 3 & 7.45 & 5.06 & 1.12 & 0.66 & $20+\mathrm{W}$ \\
Figure 4 & 3.15 & 4.11 & 1.63 & 1.05 & $20+\mathrm{W}$ \\
Figure 5 & 6.07 & 4.26 & 1.3 & 1.35 & $5-10 \mathrm{E}$ \\
\hline RMSE $_{\text {total }}$ & 27.37 & 18.5 & 9.89 & 8.56 & \\
\hline
\end{tabular}

ings. The statistics for the main and secondary break points are shown in Table 3.

From Table 3, it can be seen that the relative frequency of the heights of the inversions are well represented in both COSMIC data sets. This can also be seen in Figs. 6 and 7, where the distribution of the inversions is very similar between the three data sets. The $\mathrm{COSMIC}_{\text {wet }}$ product tends to have slightly higher and less frequent main and secondary break points than the $\mathrm{COSMIC}_{\text {raw }}$ product; however, the difference between the two COSMIC products is small. There is an anomalously high frequency of secondary inversions below $500 \mathrm{~m}$ in the COSMIC $\mathrm{Cwet}_{\text {data }}$ which is often associated with large gradients in moisture near the surface. According to Table 3, the frequency of occurrence of the two break points is significantly less in both COSMIC products compared to MAC. Therefore, the difference in vertical resolution between the two COSMIC products does not influence the frequency of main and secondary break points significantly. The statistics for the MAC data set are close to that of (Hande et al., 2012b), who use the gradient in virtual potential temperature to define the inversion heights. This implies that, statistically, the method of attributing break points in the refractivity profile to ABL interfaces is appropriate. However, there are intrinsic uncertainties in the measurement of the refractivity profile from the COSMIC products, for example the superadiabatic layers mentioned in the previous section. In terms of representing the height of the ABL, both COSMIC products offer an improvement over a highresolution reanalysis product from the ECMWF, which was found to underestimate the height of virtual potential temperature inversions by about $200 \mathrm{~m}$ (Hande et al., 2012b). Note that the ECMWF product is not included here because the vertical resolution is too coarse to reliably compute break points.

We also investigated seasonal and diurnal cycles in the height of main and secondary break points; the statistics are presented in Fig. 8. It is encouraging to note that there is a weak seasonal cycle in the heights of the break points from all data sets, with slightly higher interfaces in Southern Hemisphere summer than winter. The cycle is less notable in the secondary break points. December is a notable
Table 3. Statistics for the main and secondary break point in the refractivity profile for the MAC, COSMIC $\mathrm{wet}_{\text {and }} \mathrm{COSMIC}_{\text {raw }}$ products.

\begin{tabular}{lccc}
\hline & MAC & COSMIC $_{\text {wet }}$ & COSMIC $_{\text {raw }}$ \\
Main break point & & & \\
\hline Frequency (\%) & 66.7 & 45.8 & 48.5 \\
Mean height (m) & 1481 & 1469 & 1430 \\
Median height (m) & 1471 & 1482 & 1413 \\
Standard deviation (m) & 521 & 502 & 517 \\
\hline Secondary break point & & & \\
\hline Frequency (\%) & 38.3 & 25.7 & 29.6 \\
Mean height (m) & 821 & 809 & 795 \\
Median height (m) & 750 & 784 & 733 \\
Standard deviation (m) & 349 & 312 & 308 \\
\hline
\end{tabular}
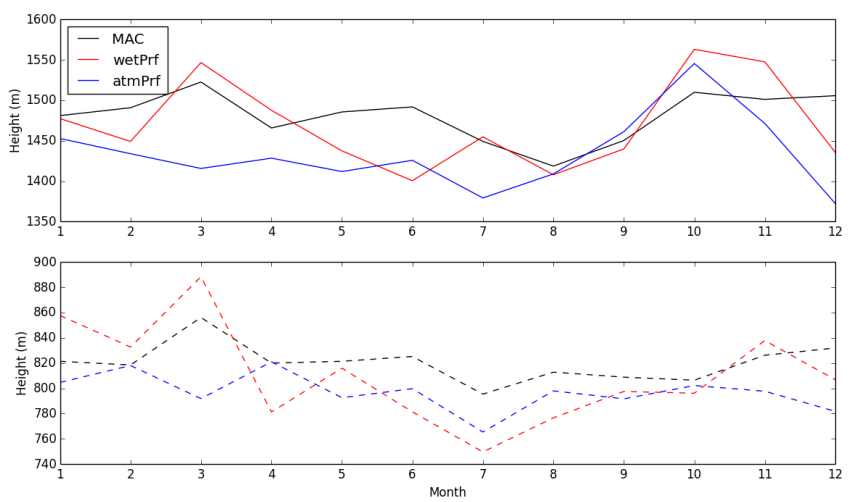

Figure 8. Seasonal cycle of main (top) and secondary (bottom) break points for MAC (black), COSMIC wet $_{\text {(red), and COSMIC }}$ raw (blue).

exception for main break points in both COSMIC products, but nevertheless, the 3-month average still preserves the seasonal cycle. However, there is no clear diurnal cycle in any of the data sets. 


\section{Conclusions}

The performance of the GPS RO technique of estimating boundary layer heights over the Southern Ocean has been evaluated. A direct comparison between co-located COSMIC RO soundings and high resolution radiosonde profiles from Macquarie Island show that both COSMIC data products identify fewer boundary layer interfaces, identified as break points in the refractivity profile. The method of identifying break points in the refractivity profile as the ABL top has merit. The tests on idealized profiles indicated that this method can reliably identify increases in temperature and/or decreases in moisture, but can have difficulties when both temperature and vapour pressure increase across the interface. This type of boundary layer structure is commonplace over the Southern Ocean. The full analysis of the 35 co-located profiles shows that there are fewer break points detected in both COSMIC products, compared to the MAC data set. However, when co-located profiles from COSMIC and MAC both identify break points, the heights of the break points mostly agree.

The ability of COSMIC wet $_{\text {et }}$ to reproduce the temperature and moisture profiles within the boundary layer was evaluated by comparison with the MAC soundings. It is shown that the COSMIC ${ }_{\text {wet }}$ product does not agree with the MAC soundings as well as the background ECMWF data, even though this product is tied to the background ECMWF data. This illustrates the potential problems of deriving thermodynamic information from COSMIC data. However, the $\mathrm{COSMIC}_{\text {wet }}$ product does show more variability in the vertical profiles, and the ECMWF data often fail to reproduce large temperature or moisture changes. This suggests that, given a more accurate and high-resolution background data set for the 1-D variational data assimilation, in may be possible to improve upon COSMIC data products.

GPS RO profiles from within a $10 \times 10$ degree box around Macquarie Island were used to perform a statistical analysis of the ability of COSMIC to reproduce the main and secondary break point heights. This indicates that, statistically, COSMIC $_{\text {wet }}$ reproduces the heights of break points in the refractivity profile well, as compared to MAC profiles. However, the frequency is much less. This is true for the raw refractivity measurements as well, which have much higher vertical resolution, indicating that the difference in the frequency of boundary layer interfaces detected is not due to differences in vertical resolution. The favourable agreement in terms of height is likely due to the break point detection algorithm using the vertical gradient of refractivity to identify break points. This essentially reverts back to the change in the bending angle, which is the fundamental COSMIC measurement. Differences between the MAC soundings and the COSMIC products should be expected due to differences in the measurement techniques between the different data sets used in this study. The different methods of averaging used to produce each data set would contribute to some of the differ- ences in the RMSE values presented in the evaluation of the thermodynamics, as well differences in estimating the ABL height and frequency.

Finally, all data sets produce a weak seasonal cycle in the heights of the interfaces, as one would expect, which is gratifying. The ability of the COSMIC products to reproduce this $\mathrm{ABL}$ feature indicates there is some merit in using the break point of the refractivity profile to identify boundary layer interfaces. This analysis shows that the COSMIC data product is most useful when analysed statistically on seasonal, or longer, timescales.

Acknowledgements. The radiosonde data were obtained from the Australian Bureau of Meteorology. COSMIC data and ECMWF data were obtained from the COSMIC Data Analysis and Archive Center (CDAAC). This research was supported by Monash University, Australia. The National Center for Atmospheric Research is sponsored by the National Science Foundation.

Edited by: T. F. Hanisco

\section{References}

Adams, N.: Model prediction performance over the southern ocean and coastal region around east antarctica, Aust. Meteor. Mag, 46, 287-296, 1997.

Albrecht, B. A., Bretherton, C. S., Johnson, D., Scubert, W. H., and Frisch, A. S.: The atlantic stratocumulus transition experimentastex, Bull. Amer. Meteorol. Soc., 76, 889-904, 1995.

Andreas, L. E.: A new sea spray generation function for wind speeds up to $32 \mathrm{~ms}^{-1}$, J. Phys. Oceanogr., 28, 2175-2184, 1998.

Anthes, R. A., Ector, D., Hunt, D. C., Kuo, Y.-H., Rocken, C., Schreiner, W. S., Sokolovskiy, S. V., Syndergaard, S., Wee, T.K., Zeng, Z., Bernhardt, P. A., Dymond, K. F., Chen, Y., Liu, H., Manning, K., Randel, W. J., Trenberth, K. E., Cucurull, L., Healy, S. B., Ho, S.-P., McCormick, C., Meehan, T. K., Thompson, D. C., and Yen, N. L.: The cosmic/formosat-3 mission: Early results, Bull. Am. Meteorol. Soc., 89, 313-333, 2008.

Ao, C., Waliser, D., Chan, S., Li, J., Tian, B., Xie, F., and Mannucci, A.: Planetary boundary layer heights from gps radio occultation refractivity and humidity profiles, J. Geophys. Res., 117, D16117, doi:10.1029/2012JD017598, 2012.

Basha, G. and Ratnam, M. V.: Identification of atmospheric boundary layer height over a tropical station using high-resolution radiosonde refractivity profiles: Comparison with gps radio occultation measurements, J. Geophys. Res.-Atmos., 114, D16101, doi:10.1029/2008JD011692, 2009.

Boers, R. and Krummel, P. B.: Microphysical properties of boundary layer clouds over the southern ocean during ace 1, J. Geophys. Res.-Atmos., 103, 16651-16663, 1998.

Bretherton, C. S., Uttal, T., Fairall, C. W., Yuter, S. E., Weller, R. A., Baumgardner, D., Comstock, K., Wood, R., and Raga, G. B.: The epic 2001 stratocumulus study, Bull. Am. Meteorol. Soc., 85, 967-978, 2004.

Chan, K. M. and Wood, R.: The seasonal cycle of planetary boundary layer depth determined using cosmic radio occultation data, J. Geophys. Res.-Atmos., 118, 12-422, 2013. 
ECMWF: Ecmwf toga 2.5 degree global surface and upper air analyses, daily 1985-continuing. Research Data Archive at the National Center for Atmospheric Research, Computational and Information Systems Laboratory, available at: http://rda.ucar.edu/ datasets/ds111.2/ (last access: 15 October 2013), 1990.

Guo, P., Kuo, Y. H., Sokolovskiy, S. V., and Lenschow, D. H.: Estimating atmospheric boundary layer depth using cosmic radio occulation data, J. Atmos. Sci., 68, 1703-1713, 2011.

Hande, L. B., Siems, S. T., and Manton, M. J.: Observed trends in wind speed over the southern ocean, Geophys. Res. Lett., 39, L11802, doi:10.1029/2012GL051734, 2012a.

Hande, L. B., Siems, S. T., Manton, M. J., and Belusic, D.: Observations of wind shear over the southern ocean, J. Geophys. Res., 117, D12206, doi:10.1029/2012JD017488, 2012b.

Huang, Y., Siems, T., Manton, S. J., Hande, M. B., and Haynes, M. J.: The structure of low altitude clouds over the southern ocean as seen by cloudsat, J. Climate, 25, 2535-2546, 2012a.

Huang, Y., Siems, T., Manton, S. J., Protat, M. A., and Delanoe, J.: A study on the low-altitude clouds over the southern ocean using the dardar-mask, J. Geophys. Res., 117, D18204, doi:10.1029/2012JD017800, 2012b.

Jensen, J. B., Lee, S., Krummel, P. B., Katzfey, J., and Gogoasa, D.: Precipitation in marine cumulus and stratocumulus. part i: Thermodynamic and dynamic observations of closed cell circulations and cumulus bands, Atmos. Res., 54, 117-155, doi:10.1016/S0169-8095(00)00040-5, 2000.

Jimi, S. I., Gras, J. L., Siems, S. T., and Krummel, P. B.: A short climatology of nanoparticles at the cape grim baseline air pollution station, tasmania, Environ. Chem., 4, 301-309, 1997.

Kursinski, E. R., Hajj, G. A., Schofield, J. T., Linfield, R. P., and Hardy, K. R.: Observing earths atmosphere with radio occultation measurements using global positioning system, Geophys. Res. Lett., 102, 23429-23465, 1997.
Rémillard, J., Kollias, P., Luke, E., and Wood, R.: Marine boundary layer cloud observations in the azores, J. Climate, 25, 73817398, 2012.

Russell, L. M., Lenschow, D. H., Laursen, K. K., Krummel, P. B., Siems, S. T., Bandy, A. R., Thornton, D. C., and Bates, T. S.: Bidirectional mixing in an ace 1 marine boundary layer overlain by a second turbulent layer, J. Geophys. Res., 111, 391-426, 1998.

Schreiner, W., Rocken, C., Sokolovskiy, S., Syndergaard, S., and Hunt, D.: Estimates of the precision of gps radio occultations from the cosmic/formosat-3 mission, Geophys. Res. Lett., 34, L04808, doi:10.1029/2006GL027557, 2007.

Seidel, D. J., Ao, C. O., and Li, K.: Estimating climatological planetary boundary layer heights from radiosonde observations: Comparison of methods and uncertainty analysis, J. Geophys. Res.Atmos., 115, D16113, doi:10.1029/2009JD013680, 2010.

Sokolovskiy, S., Kuo, Y. H., Rocken, C., Schreiner, W. S., Hunt, D., and Anthes, R. A.: Monitoring the atmospheric boundary layer by gps radio occultation signals recorded in the open-loop mode, Geophys. Res. Lett., 33, L12813, doi:10.1029/2006GL025955, 2006.

Stull, R.: An introduction to boundary layer meteorology, Vol. 13, Springer, 1988.

Trenberth, K. E. and Fasullo, J. T.: Simulation of present-day and twenty-first-century energy budgets of the southern oceans. Journal of Climate, 23, 440-454, 2010.

Vinoth, J. and Young, I. R.: Global estimates of extreme wind speed and wind height, J. Climate, 24, 1647-1665, 2011.

Xiaojun, Y.: High-wind-speed evaluation in the southern ocean, J. Geophys. Res., 119, D13101, doi:10.1029/2003JD004179, 2004.

Young, I. R., Zieger, S., and Babanin, A. V.: Global trends in wind speed and wave height, Science, 332, 451-455, 2011. 